\title{
Competitiveness Education Strategies in Training Experts for Coal Mining Region
}

\author{
Olga Mityakina ${ }^{1}$, Elena Monastyrskaya $^{1}$, Maria Silkova ${ }^{1}$ \\ ${ }^{1}$ Kemerovo State University, Institute of Philology, Foreign Languages and Mediacommunications, \\ Department of Foreign Languages, 650000, 6 Krasnaya st., Kemerovo, Russia
}

\begin{abstract}
Methods and strategies of developing students' skills for further successful employment in coal-mining region are considered. Combined techniques as to let students demonstrate their competitiveness abilities and qualifications are studied and criteria of objective assessment and expert advice are presented. The process of globalization has significant impact not only on industrial sphere all over the world but it has affected a lot of other human activities, and mining education is not an exception. Innovative determinant of mining education globalization obviously implies the need of integrating both technical and humanitarian subjects while training prospective experts. Combining different methods helps students develop their competitiveness abilities estimated highly in the coal mining labor market. The important methods of forming graduates' readiness to compete in coal mining industry activate the linguistic representation of different aspects of employment by means of pedagogic techniques within humanitarian disciplines. The main stages of the comprehensive method named assessment-centre are also shown. So, developing students' competitiveness ability for successful employment in the sphere of coal mining industry includes both theoretical and practical training to provide effective information searching for vacancies and distributing information about themselves as applicants as well as successful job interview in coal mining region.
\end{abstract}

\section{Introduction}

Coal mining industry globalization has caused the emergence of new technologies, changes in economic and social spheres, and it has obviously impacted the system of training experts for coal mining region. According to Federal State Educational Standard Russian universities are focused on training highly-qualified experts with a wide range of soft skills and the ability to navigate in the labor market as well as advantageously introduce themselves and compete with other job-seekers. Therefore one of the tasks of the Russian higher school is to create conditions for training graduate able to compete in the labor market.

University graduates enter the labor market as applicants for a job. The ability of the applicants to obtain the desired working place is connected with their competitiveness. The stage of employment is just the first stage when the applicants show their competitiveness. The term "employment" refers to the process of jobs selection and executing an 
employment agreement with a certain employer. Generally speaking, the employment process is any process of applying for a job self sufficiently or by means of special bureaus.

The information about job opportunities and vacancies suitable for students and graduates of Kemerovo State University is constantly distributed by the special university department. Our research has shown that information on vacancies is interesting not only for seniors but also for juniors. The vast majority of our first-year students would like to combine work and study. Over $80 \%$ of respondents are planning to start their career in the senior years, and $10 \%$ would start to work already in the first year of education.

The administration and higher educational teaching personnel are involved in forming readiness of graduates to compete in the coal mining labor market. The official website of the university displays detailed information about vacancies for graduates and students, recommendations how to create a resume and avoid the first mistakes in job-seeking, etc.

Innovative determinant of mining education globalization obviously implies the need of integrating both technical and humanitarian subjects while training prospective experts. That is why teaching personnel train students in getting competitiveness skills not only within their disciplines and in extracurricular work but they also integrate several disciplines together. Significant contribution in preparing students for successful applying for a job at the phase of employment is provided by the teachers of such subjects as "Russian language and speech culture", "Foreign language", "Psychology". They help students gain a full understanding about the procedure of employment, acquire the necessary skills and abilities to form certain qualities and obtain the desired working place.

We offer our students to look at the process of employment both like an applicant and employer. And this is the key element of our approach in forming graduates' competitiveness in the labor market.

\section{Materials and methods}

In developing students' skills for further successful employment in coal-mining region there have been used such methods and materials as reviewing regulatory documents on developing students' competences for further successful employment, searching and analyzing the information related to this field, observing and comparing the data obtained by analyzing the students' readiness to compete in the labor market. There have been also used some pedagogical methods as to let students demonstrate their competitiveness abilities and qualifications when applying for a job [1-4].

The procedure of employment begins with a job seeking. Experts claim that insufficiency of information necessary for employers and for graduates either is one of the negative factors for successful employment. Employers and graduates often do not know about each other. According to the received data, first-year students are not clear about where to find reliable information about vacancies. About $50 \%$ of juniors are going to look for a job through ads on television or via the Internet. We provide students with all available channels of information distribution that employers use, about all the vacancies and ways of staff recruitment [5-7]. The last ones are searching among friends, placement of announcements in public places, placement of ads in newspapers, looking through web sites, contacting employment services and recruitment agencies, participation in specialized job fairs, cooperation with universities. We pay special attention to job searching among friends and acquaintances. It turned out that only 22 percent of the students were going to take the help of friends and acquaintances in seeking the job, i.e. the rest of the students did not plan to use their existing social capital. Social capital is understood as the structure and quality of informal ties. It is obvious that becoming a professional means not only formal training in educational or vocational programs, but also in the process of informal interactions with other people, sharing knowledge and experience. Social capital 
accumulated by the students expands their opportunities to obtain a job and positively influences the evaluation of a student's own employment prospects after graduation.

We draw students' attention to the fact that HR managers actively use personal relations while searching for applicants with the required skills, since it helps collect sufficient information about them. That is why it is so important to let as many people as possible (relatives, friends, friends parents, etc.) know that a student is looking for a job and have necessary information about an applicant. Some students confess that they are embarrassed to ask friends and, especially, less familiar people. In such cases we help students overcome this psychological barrier cooperating with the faculty of psychology [8-11].

The next step in the employment process is writing a resume. The person who wants to get a job provides the information that could make him or her suitable in the eyes of an employer. Students can find guidelines for resume and samples on the Internet, on the website o four university, in the special literature. There are lots of sources. Our students obtain a fairly comprehensive list of such sources. But to learn how to write a resume needs practicing. Therefore, teachers of such disciplines as "Russian language and speech culture" and "Foreign language" pay great attention to forming practical skills of resume writing.

In order to allow students understand better the activities of employers in the recruitment and selection of staff, we have compiled a glossary of terms for employment, which includes both Russian-speaking traditional terms and widely used English terms also need to know when applying for a job: the recruiter, the HR Headhunter, etc.

Teachers of the university use combined techniques as to let students demonstrate their competitiveness abilities and qualifications. Besides, students get expert advice and essential criteria of objective assessment in the recruitment process. Students acquaint with the types of resume (basic, narrative, chronological, functional, and combined) and study the structure and style. After that students write resumes of different types on behalf of themselves and on behalf of someone else. Then they are to analyze merits and flaws of their fellow learners' resumes. This happens in the form of a role play in which students play the role of HR managers and applicants. We provide students with information on how HR managers operate with resumes received. True professionals see not only what is written in the resume, but what the candidate has not mentioned. Students playing as HR managers assess the resumes and decide whether students-applicants can be considered as potential candidates. Then they justify their choice to the head of the department. This role can be played by a student or a teacher. It should be noted that these tasks are of great interest among students.

The possibility that the applicant will get a vacant position increases greatly if a resume has a portfolio appended. There are different types of portfolios: "portfolio documentation", "portfolio-header", "portfolio showcase", "portfolio evaluation", "portfolio reviews", "portfolio achievements", "on-line portfolio". However, the analysis of the literature on the problems of employment and competitiveness of applicants shows that the attention of HR managers is attracted, first of all, by portfolios of achievements. Therefore, starting from the first months of teaching students we encourage them to create such a portfolio. Students are advised to collect all the documents that confirm their achievements both in academic and extracurricular activities. These documents include diplomas for participation and victory in sport events, letters of appreciation, testimonials, certificates of laureate of allRussian competitions, awards, certificates of participation in scientific conferences and competitions, etc. Portfolio of achievements will allow the employer to identify the applicant's potential, assess his or her abilities and opportunities, i.e. the employer will get a coherent picture of applicant's professional competences, soft skills and personal qualities.

The final phase of job seeking and resumes' distribution is an invitation for an interview. While teaching we consider the following questions: how to interview, how to behave, what to say in the interview. These questions concern the applicants for a job, and 
knowing the answers is one of the conditions for a successful interview. To answer these questions students learn the definition of term "the interview" and the interview types. The interview is a non-public conversation with candidates in selecting and applying for a job that goes according to plan. The interview has two main purposes: 1) to help organizations evaluate candidates for the offices; 2) to help the candidates to assess the organization as a future place of employment. The most common types of interview are psychological, professional and biographical. Students learn the distinguishing features of these types of interviews and methods of their realization. The interview usually includes the following types of questions: biographical, projective and questions of competency. Biographical questions are related to the facts of the applicant's life. Projective questions are about acts the applicant would do in a hypothetic situation. And competence questions are about how and in what particular situations the applicant has demonstrated the competencies assessed.

We prepare students for what employers are interested in. First of all whether applicants possess such competences as skills of communication (persuasion and argumentation, presentation, conflict resolution, understanding of the interlocutor); collaboration or teamwork; results orientation; skills of work with information (analysis, logic, structuring); the skills of planning and organization; development orientation; leadership skills. According to experts, during the interview the participants have the greatest difficulties when they answer the questions on competences and have to remember specific situations from their own professional and life experience.

Prospective graduates should be aware that, as a rule, the recruitment experts have the necessary knowledge in the field of psychology, general erudition, good memory, discernment, ability to speak and listen, patience and flexibility. HR managers are good psychologists and attentively watch for non-verbal human behavior. That is why special attention is paid to nonverbal communication. Students get acquainted with the concepts of kinesics, proxemics, paralinguistics, cognitive science, metalinguistics, visual communication, takesics. According to our observations the students get interested in studying the materials and performing practical tasks aimed at the acquisition of knowledge about nonverbal communication and the ways to develop nonverbal communication skills.

Preparing students for the interview includes the formation of skills of self-presentation. Self-presentation is an inherent part of any social communication and is defined as an ongoing process of presenting the information in interpersonal interaction, regardless of a person's awareness about their behavioral actions. Finding themselves in a situation of social interaction with an individual or a group of people a person becomes the subject of self-presentation, presenting the partner of communication (the object of self-presentation) information about themselves, which is expressed through symbolic signs. The literature indicates the need for special training to self-presentation, as it makes the first impression on HR managers. Students were given a task to speak in front of the group about their experience, goals and plans. They were also asked to consider how to talk about their weaknesses because such questions are often asked and it is not always easy to find answers.

Non-verbal means of communication are considered important in self-presentation. That is why we developed the complex of the tasks directed on formation of necessary skills. In the framework of the course "Business foreign language" students were asked to prepare an informational message about the ability to recognize the degree of sincerity of a person by his movements. Some students carried out this task with the use of visual AIDS in the form of slides. Other students worked with the special literature as to make a survey of keeping the correct distance in various situations, which positively affects favorable evaluation of other people.

Another type of tasks performed by the students is making the sketch about the speed and manner of speech, voice volume, intonation and clarity of pronunciation. The students 
explained in their sketches that the successful performance required considering a substantial part of the talk, controlling the speed of the speech, speaking strongly and confidently, etc. Then students analyzed the questionnaires with the most important questions for an interview. They also made questionnaires in foreign languages. The students made the glossary "the Interview" and crossword puzzles both in Russian and a foreign language. It helped them systemize the topic information.

It was students' initiative to prepare materials and create a presentation about how to be and how not to be dressed for an interview. They demonstrated it on their classmates as the models. The execution of all tasks ended by collective or individual reflection about what they saw and heard.

The willingness of students for an interview is effectively assessed by the role play. That is why our teachers use the method of role plays when developing competitiveness skills of students. The role play is performed in accordance with a pre-designed scenario. Some students become candidates for the vacancy. Other students act as HR managers, and the effectiveness of the participants are estimated by the observers (teachers and students).

Student-candidates for the vacancy receive certain instructions, one of which is to make deliberate errors. The students-HR managers are to identify mistakes in the behavior of the candidates, i.e. to pay attention to the verbal and nonverbal means of communication, as it is necessary to determine the degree of sincerity of the applicant in the interview. During the execution of the task the teacher and student-observers record the words and actions of each participant as to have material for discussion and evaluation. At the end of the game the students and the teacher analyze the actions and behavior of each participant. As a rule students note that the game give them the opportunity to understand how to behave in a certain situation. They intend to apply developed knowledge, techniques and skills real life. The teacher identifies what personal and professional qualities students express during the game, how they manifest their knowledge and abilities, i.e. whether they display competitiveness skills. The interview is one of the most important stages of employment and a means of evaluating the applicant's communicative and professional competence.

The most complete picture of the applicant, his or her personal qualities and professional competencies is achieved by using assessment center. The assessment center is a systematic method that allows employers to determine not only personal qualities, but also strengths and weaknesses of the employee in the occupational field. Observers declare their requirements in advance and simultaneously to all participants. This is a combined method of personnel's evaluation that most of prestigious companies extensively use.

Taking into account the importance and significance of the successful employment of our graduates, their willingness to work in prestigious companies our teaching staff acquaint students with assessment center. The teachers of humanitarian, social and economic cycle and special disciplines cooperate and conduct training assessment centers for students at Kemerovo State University. According to special literature on assessment centers this method includes specially selected test tasks and individual exercises, business games and role plays, discussions and other tasks that let applicants display their professional competence and personal qualities. It allows us to determine the stages of the assessment center and their contents.

At the first (preparatory) stage students are given general information about the assessment center, and then each stage is discussed in details. And only after that the processing of the assessment center begins.

The second stage of the assessment center includes personality tests, interpersonal relations tests, and intellectual tests. The purpose of this stage is to identify the personality characteristics of the participants, their merits and flaws, communication style and level of intellectual development. Teachers of psychology responsible for carrying out this stage, explain students that the answers to the questions are not divided into correct and incorrect, 
so it is necessary to answer honestly and openly. The students are informed that real tests can identify such qualities as dishonesty, propensity for theft, greed, lack of soft skills, etc., techniques that help to diagnose addiction to alcohol and drugs, and mental disability are also used. This information often causes mixed reactions of students. Many of them consider such a check humiliating. Others agree that employers have the right to protect themselves from possible troubles. At the processing of our assessment centers we do not subject students to such tests. As for intelligence tests, the students are recommended to practice independently in tests on general intelligence as to prevent confusion while passing the training assessment and the real assessment center in the future.

The third stage of the assessment is an interview and self-presentation. We train students in advance and this helps them successfully pass through this stage. In real life specially prepared observers (external consultants, personnel services staff or specially prepared managers) assess the behavior of the participants. They watch how the applicants exhibit certain competencies, and evaluate on the base of the developed scale for assessment of individual skills. In our training assessment centre the function of observers is performed by the teachers and the personnel services staff.

The fourth stage (that is the main one) the assessment center typically involves discussions, business and role-playing games.

At the fifth (final) stage participants are announced about the tests results and observers' evaluation. Students, who have questions about the results and estimates, have the opportunity to ask teachers and specialists conducting the assessment for clarification and recommendations.

\section{Results and Discussion}

In our assessment center we have trained 60 4th course students of the economic faculty at Kemerovo State University. According to received results $84.2 \%$ of students believe that the experience they got is necessary and useful, and the participation in the training assessment centre prepared them to pass the real assessment center more confidently and successfully. The least part of the students (15.8\%) think that being trained in the assessment centre was interesting but they are unlikely to participate in such testing when applying for a job in the future. It seems to them that the actual employment procedure is much easier and getting a job depends on the subjective attitude of the employer.

The vast majority of students (79.6\%) claim that they took a fresh look at themselves, perceived their strengths and weaknesses. They have a desire to develop their strengths and eradicate shortcomings. However, $12 \%$ of participants believe that they learned nothing new about themselves, and $8.4 \%$ do not agree with the test results and assessments of their competencies and qualities by observers.

\section{Conclusion}

According to data received we can generally conclude that competitiveness education strategies in training experts at Kemerovo State University are necessary and effective. Developing students' competitiveness ability for successful employment in the modern labor market includes both theoretical and practical training to provide effective information searching for vacancies and distributing information about themselves as applicants as well as successful job interview. The important methods of forming graduates' readiness to compete in coal mining industry activate the linguistic representation of different aspects of employment by means of pedagogic techniques within humanitarian disciplines. Students learn to write different types of resumes using the 
correct vocabulary and appropriate grammar models. They are also trained to present their merits as advantageously as possible, and successfully pass the assessment center and interview. The assessment center allows students to demonstrate their knowledge, skills, competencies and personal qualities, and to get objective assessment, to hear the recommendations of experts for further self-development. It also helps to make reasoned decisions about further employment and career planning.

Thus, combining different methods and integrating technical and humanitarian subjects while training prospective experts at Kemerovo State University provides effective developing students' skills for further successful employment in coal-mining region.

\section{References}

1. H. B. Allen, R. N. Campbell, Teaching English as a Second Language (McGowanHill, New York, 1972)

2. J. J. Asher, The Modern Language Journal, 53, 3-17 (1969)

3. S. Bax, ELT Journal, 57:3, 278-287 (2003)

4. T. S. Duncan, J. Paradis, Journal of Speech, Language, and Hearing Research, 1:39 (2016)

5. R. Felder, Learning and Teaching Styles in Foreign and Second Language Education, 28:1, 21-31 (1995)

6. J. O. Gary, Native Language and Foreign Language Acquisition (New York Academy of Sciences, New York, 1981)

7. J. Harmer, The Practice of English Language Teaching (Pearson Education Ltd., Essex, 2001)

8. R. M. Hummel, Linguistics in the World Introducing Second Language Acquisition: Perspectives and Practices (Wiley-Blackwell, Somerset, 2013)

9. W. Littlewood, Communicative language teaching (Cambridge University Press, Camblodge, 1981)

10. J. Richards, Communicative Language Teaching Today (Cambridge University Press, Camblodge, 2006)

11. J. Richards, Approaches and Methods in Language Teaching (Cambridge University Press, Camblodge, 1981) 